\title{
Direction of Flap Rotation in Propeller Flaps: Does It Really Matter?
}

\author{
Sinyoung Song, $\mathrm{MD}^{1}$ Hyung Hwa Jeong, $\mathrm{MD}^{1}$ Yeonhun Lee, $\mathrm{MD}^{1}$ Hollie Powers, MD ${ }^{1}$ \\ Young Chul Suh, MD ${ }^{1}$ Phaedon Christoffi, MD ${ }^{1}$ Hyunsuk Peter Suh, MD, PhD ${ }^{1}$ \\ Joon Pio Jp Hong, MD, PhD, MMM${ }^{1} \odot$
}

${ }^{1}$ Department of Plastic Surgery, Asan Medical Center, University of

Ulsan, Seoul, Korea

J Reconstr Microsurg 2019;35:549-556.

\begin{abstract}
Address for correspondence Joon Pio Hong, MD, PhD, MMM, Department of Plastic and Reconstructive Surgery, Asan Medical Center, University of Ulsan Collage of Medicine, 388-1 Pungnap-dong, Songpa-gu, Seoul, Asan Medical Center, Seoul, 138-736, Korea (e-mail: joonphong@amc.seoul.kr).
\end{abstract}

\begin{abstract}
Keywords

- propeller flaps

- rotation of flaps

- perfusion of flaps

Background This article investigates the effect of $180^{\circ}$ rotating propeller flaps and evaluates whether each flap has a "preferable" rotating direction.

Methods Part 1 evaluates the flap pedicle velocity and flow volume in neutral, $180^{\circ}$ counterclockwise, and clockwise rotated position for 29 consecutive flaps. The data (velocity and volume) were divided into three groups: neutral, high value, and low value group then evaluated. Part 2 compares the outcome from the prospective study where a preferable rotation with high value was selected against 29 patients from 2012 to 2016 who had the same operation without selecting a preferable rotation direction.

Results In part 1, the three groups (neutral, high value, and low value groups) showed mean velocity of $28.06 \pm 7.94,31.92 \pm 10.22,24.41 \pm 8.12 \mathrm{~cm} / \mathrm{s}$, respectively, and mean volume of $6.11 \pm 4.95,6.83 \pm 6.69,4.62 \pm 3.55 \mathrm{~mL} / \mathrm{min}$, respectively. The mean velocity and volume of the perforator in the high value group were significantly higher than that in the low value group $(p=0.0001)$. In part 2 , although no statistical significance in the outcome was observed, there were two cases of total, two cases of partial flap loss, and three cases of wound dehiscence in the patients where preferable rotations was not selected compared with only two wound dehiscence for flaps with preferable rotation.

Conclusion The velocity and flow of the flap are significantly different based on the rotation direction of the flap. Using the preferred rotation direction with statistically higher value of velocity and flow may increase the overall outcome of the propeller flap, especially where larger flaps are used.
\end{abstract}

The use of perforator flaps has steadily increased since the introduction of the concept by Koshima and Soeda. ${ }^{1-3}$ The perforator flaps offer the advantages of sparing the underlying muscle, resulting in decreased donor-site morbidity. Hyakusoku et al first used the term "propeller flap" in 1991, to describe

(1) Hollie Power's ORCID is https://orcid.org/0000-0003-1131-5940. (D)Joon Pio Hong's ORCID is https://orcid.org/0000-0002-62089704.

received

December 28, 2018

accepted after revision

February 21, 2019

published online

May 10, 2019 subcutaneous pedicled island flaps vascularized by a perforator artery and rotated $90^{\circ}$ to reconstruct the defect after release of scar contractures in a burn patient. ${ }^{4}$ Once a propeller flap has a reliable vascular pedicle, it can be easily mobilized and rotated as a local flap. Furthermore, the harvest is fast and easy and may not require microsurgery. ${ }^{2}$ In 2006, combining the concept of propeller flaps and perforator based flaps, Hallock reported a fasciocutaneous flap that was similar in shape to the one described by Hyakusoku et al and further showed that

Copyright $\odot 2019$ by Thieme Medical Publishers, Inc., 333 Seventh Avenue, New York, NY 10001, USA.

DOI https://doi.org/ 10.1055/s-0039-1688408. ISSN 0743-684X. 
skeletonization of a perforating vessel and rotation up to $180^{\circ}$ on an eccentric pivot point was viable. ${ }^{1,4-6}$ The direction of rotation depends on the angle between the proximal long axis of the flap and the defect thus preferring any rotation less than $180^{\circ}$.

To achieve successful perforator-based propeller flap reconstruction, maximizing the flow to the flap via the pedicle is critical. According to previous reports, studies have been performed to investigate the number, length, and angle of rotation that affect blood flow into the flap. ${ }^{7,8}$ During flap transposition, the perforators are twisted to different extents due to the topographical relationships between the defect and donor sites. Factors such as kinking, twisting, and tension on the pedicle are well known causes of flap failure and can be harmful even in nonanastomotic conventional flap and perforator flap models. ${ }^{7,9-11}$ When rotation is only needed up to $90^{\circ}$, it may not matter whether more than one pedicle is preserved. However, when the flap needs to be rotated $180^{\circ}$ it is actually safer to divide all perforators except one to prevent potential hazards like pedicle kinking and one perforator compressing the other. ${ }^{1}$ It is well known that obtaining a longer pedicle improved survival of a twisted perforator flap in a rat model. ${ }^{8}$

Despite the research done on various conditions of the perforator in propeller flaps, there has been no evidence that the direction of rotation can be significant. Does the direction of rotation matter when the flap has to undergo $180^{\circ}$ of rotation? The question was asked by Schonauer et al and showed there is a favorable direction based on clinical observation. ${ }^{12}$ We expanded this concept to investigate the effect of $180^{\circ}$ rotation on propeller flap flow dynamics. We hypothesized that every propeller flap has a favorable (preferred) direction of rotation that optimizes the perfusion into the flap.

\section{Patients and Methods}

\section{Part I. Prospective Study}

Consecutive patients who had perforator-based propeller flaps on the lower extremity or trunk that needed $180^{\circ}$ rotation were enrolled to the study from December 2016 to January 2018.

\section{Data Grouping, Flap Pedicle Flow Velocity, and Flow Volume Rate Measurement}

In all cases, $180^{\circ}$ flap rotation was required to cover the defect. Perforator flow velocity and flow volume rate measurement were then performed at three different time points after the elevation: neutral (as a control and prior to any rotation), counterclockwise, and clockwise $180^{\circ}$ rotated position. The data was then divided into three groups: neutral, high value (flow velocity and flow volume rate), and low value (flow velocity and flow volume rate) group. We compared mean flow velocity and flow volume rate if there was a significant difference between each group.

Flap size, final rotation direction, and short-term and long-term complications (partial loss and its dimension) were recorded. The overall characteristics of the patients are shown in - Table 1 ("Duplex + clinical exam" group).
Table 1 The clinical and wound characteristics for the prospective group (using Duplex and clinical examination) and retrospective group (clinical examination only)

\begin{tabular}{|c|c|c|c|}
\hline Characteristic & $\begin{array}{l}\text { Duplex }+ \\
\text { clinical exam } \\
\text { (prospective } \\
\text { group) }\end{array}$ & $\begin{array}{l}\text { Clinical } \\
\text { exam only } \\
\text { (retrospective } \\
\text { group) }\end{array}$ & $p$-Value \\
\hline $\begin{array}{l}\text { Number of } \\
\text { patients }\end{array}$ & 29 & 29 & \\
\hline \multicolumn{4}{|l|}{ Defect etiology } \\
\hline DM foot & 2 & 0 & \\
\hline Malignancy & 18 & 22 & \\
\hline Pressure sore & 5 & 4 & \\
\hline COM & 1 & 1 & \\
\hline Trauma & 3 & 2 & \\
\hline Defect location & 29 & 29 & \\
\hline Foot & 2 & 1 & \\
\hline Leg & 7 & 12 & \\
\hline Trunk & 19 & 15 & \\
\hline Upper back & 1 & 1 & \\
\hline Lower back & 5 & 2 & \\
\hline Flank & 1 & 1 & \\
\hline Buttock & 4 & 3 & \\
\hline Sacrum & 5 & 5 & \\
\hline Ischium & 2 & 1 & \\
\hline Abdomen & 0 & 1 & \\
\hline Groin & 1 & 1 & \\
\hline Upper extremity & 1 & 0 & \\
\hline Face & 0 & 1 & \\
\hline \multicolumn{4}{|l|}{ Rotation direction: } \\
\hline CCW & 13 & & \\
\hline $\mathrm{CW}$ & 16 & & \\
\hline Degrees of rotation & 180 & 180 & \\
\hline Flap size, $\mathrm{cm}^{2}$ & $\begin{array}{l}107.6 \mathrm{~cm}^{2} \\
\text { (range: } \\
16-300 \text { ) }\end{array}$ & $\begin{array}{l}107.8 \mathrm{~cm}^{2} \\
\text { (range: } \\
16.5-198 \text { ) }\end{array}$ & \\
\hline \multicolumn{4}{|l|}{ Complications: } \\
\hline Total flap loss & 0 & 2 & 0.491 \\
\hline Partial flap loss & 0 & $2^{\mathrm{a}}$ & 0.491 \\
\hline Minor revision & $2^{b}$ & $3^{c}$ & 0.999 \\
\hline
\end{tabular}

Abbreviations: CCW, counterclockwise; COM, chronic osteomyelitis; $\mathrm{CW}$, clockwise; DM, diabetes mellitus.

${ }^{\mathrm{a}} \mathrm{Flap}$ loss less than $50 \%$ of flap size.

b'Wound dehiscence, hematoma evacuation, and delayed closure.

${ }^{c} M a r g i n$ dehiscence, superficial partial flap necrosis.

\section{Surgical Procedure}

Potential perforators were screened using a handheld Doppler anticipating the defect the night before the operation. Then Duplex was used to further identify the exact point of the perforator and to map the direction and branching patterns (-Fig. 1). ${ }^{13}$ A LOGIQ E9/GE (GE Healthcare, Milwaukee, WI) 


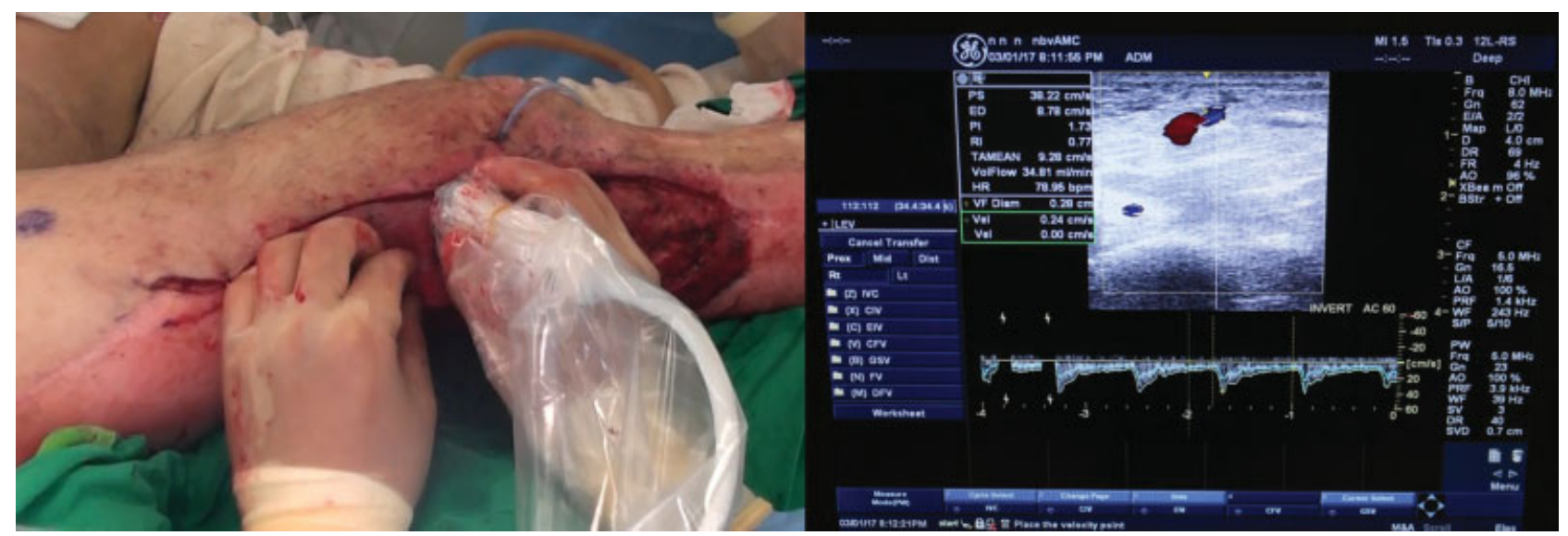

Fig. 1 Velocity and volume of the perforator was measured at three different positions of the flap after elevation using a Duplex: neutral (as a control and prior to any rotation), counterclockwise, and clockwise $180^{\circ}$ rotated position. The Duplex probe is placed over the perforator to obtain the flow velocity and flow volume rate.

with 12L-RS (5-13MHz) was used. In pulse wave Doppler Mode, the hemodynamic parameters are displayed with characteristic curves. As a quantitative parameter for flow velocity, the peak systolic velocity $(\mathrm{cm} / \mathrm{s})$ was used. To obtain the flow volume rate, VolFlow ( $\mathrm{mL} / \mathrm{min})$ was measured.

After the defect is clearly identified, the flap is designed based on the previous markings made using the Doppler. Initial incision is made on one side of the flap and dissection plane can be either subfascial or suprafascial depending upon each situation. After identifying the potential perforators, final selection is based on the pulse (visual pulsation), location of the perforator (closer to the defect), and the diameter (preferably larger). ${ }^{14-16}$ Once the pedicle is determined, final design is drawn to accommodate the defect to achieve primary closure of all of the donor sites; flap design was based on the skin laxity often ending in $180^{\circ}$ rotation. All the flaps were based on a single perforator in this series. The pedicle is skeletonized enough to accommodate absolute tension free rotation under $3.5 x$ loupe magnification but rarely reached the source vessel ( - Fig. 2). The flow velocity and flow volume rate are verified using the Duplex. After obtaining information from the Duplex in regard to flow velocity and flow volume

\section{A}

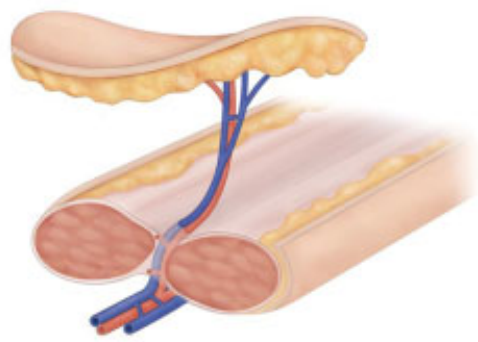

B
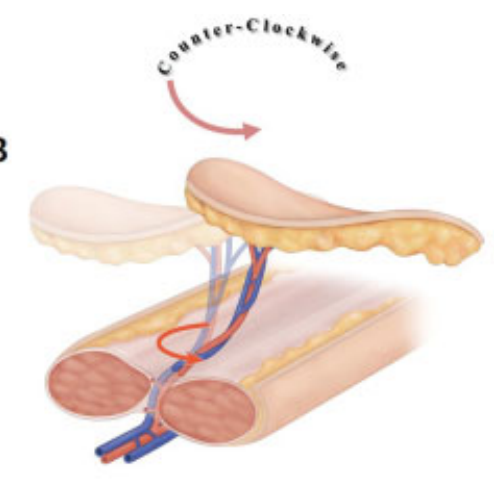

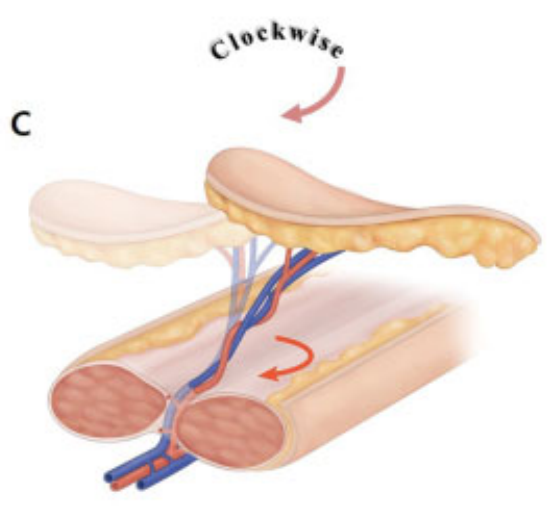

Fig. 2 The flow velocity and flow volume rate can be measured using a Duplex over the perforator. The measurement value is shown on the screen of the Duplex. Three different measurement were made based on the flap position: neutral, $180^{\circ}$ clockwise rotation, and $180^{\circ}$ counterclockwise rotation. 
rate, the flap was rotated in the direction revealing higher flow velocity and flow volume rate (- Video 1 ).

\section{Video 1}

Then Duplex can be used to identify the exact point of the perforator, to map the direction, branching patterns, and physiologic values such as velocity and volume. The measurement of the flow velocity and volume is performed using a Duplex scan in three different positions of the flap in the operating room. Online content including video sequences viewable at: https://www.thieme-connect.com/products/ ejournals/html/10.1055/s-0039-1688408.

\section{Part II. Comparison between Retrospective and Prospective Data}

Retrospective data on flap outcome was obtained from 29 patients from 2012 to 2016 who had perforator-based propeller flaps on lower extremity and trunk that needed $180^{\circ}$ rotation. In these patients, the flap rotation was not based on any measurement other than clinical judgement. The characteristics of the patients are shown in - Table $\mathbf{1}$ ("Clinical exam only" group). The data was then compared with the prospective cohort to evaluate whether direction selection based on higher flow velocity and flow volume rate affected the overall results.

\section{Statistical Analysis}

SPSS version 21.0 was used for data analysis (IBM, Armonk, NY). Descriptive statistics were calculated for each variable. Continuous variables were compared using Wilcoxon signed-rank test and categorical variables were compared using Fisher's exact test. $p$-Values $<0.05$ were considered statistically significant.

\section{Results}

\section{Part I}

Flow Velocity and Flow Volume Rate Assessment in Prospective 29 Cases

Based on the 29 cases, the three groups (neutral, high value, and low value groups) showed mean flow velocity of $28.06 \pm 7.94$,
$31.92 \pm 10.22,24.41 \pm 8.12 \mathrm{~cm} / \mathrm{s}$, respectively, and mean flow volume rate of $6.11 \pm 4.95,6.83 \pm 6.69,4.62 \pm 3.55 \mathrm{~mL} / \mathrm{min}$, respectively. In all cases, the relationship between flow velocity and flow volume rate was directly proportional.

The mean flow velocity of the perforator in the high value group was not statistically different than the neutral group $(p=0.117)$. The high value group had a significantly higher flow velocity than the low value group $(p=0.0001)$. The perfusion flow volume rate was also significantly higher for the high value group when compared with the low value group ( $p=0.0001$ ) (-Table 2, -Fig. 3 ).

Among the 29 cases, 16 cases were measured as high value when the flap turned clockwise and 13 cases were measured as high value when it turned counterclockwise without significant difference.

In 29 cases, the mean flap size was $107.6 \mathrm{~cm}^{2}$ with mean follow-up period of 8 months (range: $3-13$ months). There were no adjuvant chemotherapy or radiotherapy involved. All propeller flaps survived without major incident requiring secondary surgery. Two cases of wound dehiscence were noted but healed by secondary intention.

\section{Part II}

Twenty-nine cases of retrospective review had mean flap size $107.8 \mathrm{~cm}^{2}$ and 16 cases of $180^{\circ}$ clockwise rotation, 13 cases of $180^{\circ}$ counterclockwise rotation. The mean follow-up period was 26 months (range: from 12 to 36 months) and no adjuvant chemotherapy or radiotherapy was given. There were two cases of total flap loss, two cases of partial flap loss, and three cases of wound dehiscence.

When comparing the flap survival data between the retrospective study and prospective study, there was no significant difference between the two groups in complications ( $p=0.1443$ ) ( - Fig. 4). Flap sizes for the two cases of total flap loss were $105 \mathrm{~cm}^{2}(15 \times 7 \mathrm{~cm})$ and $128 \mathrm{~cm}^{2}$ $(16 \times 8 \mathrm{~cm})$ and followed resection of malignancies on the lower extremity and buttock, respectively. Flap sizes for the two cases of partial flap loss were $180 \mathrm{~cm}^{2}(20 \times 9 \mathrm{~cm})$ and $110.5 \mathrm{~cm}^{2}(13 \times 8.5 \mathrm{~cm})$ and followed resection of malignancies on the buttock and shoulder, respectively.

\section{Discussion}

Despite improved understanding of the skin blood supply and advances in reconstructive techniques, flap failure remains a significant problem. According to the review

Table 2 The measured values after reorganization into neutral, high, and low value groups

\begin{tabular}{|l|l|l|l|l|l|l|}
\hline & Neutral & High & Low & & & \\
\hline & & & & Velocity & Volume & $p$-Value \\
\hline Velocity $(\mathrm{cm} / \mathrm{s})$ & $28.06 \pm 7.94$ & $31.92 \pm 10.22$ & $24.41 \pm 8.12$ & & & \\
\hline Volume $(\mathrm{mL} / \mathrm{min})$ & $6.11 \pm 4.95$ & $6.83 \pm 6.69$ & $4.62 \pm 3.55$ & & & \\
\hline$\Delta 1$ & & & & 3.86 & 0.72 & $0.059 / 0.627$ \\
\hline$\Delta 2^{*}$ & & & & 7.50 & 2.21 & $0.0001^{*} / 0.0001^{*}$ \\
\hline
\end{tabular}

Note: The high value group had a significantly higher flow velocity and flow volume rate compared with the low value group ( $p=0.0001)$. $\Delta 1$ : High - Neutral; $\Delta 2$ : High - Low. *Statistically significant. 


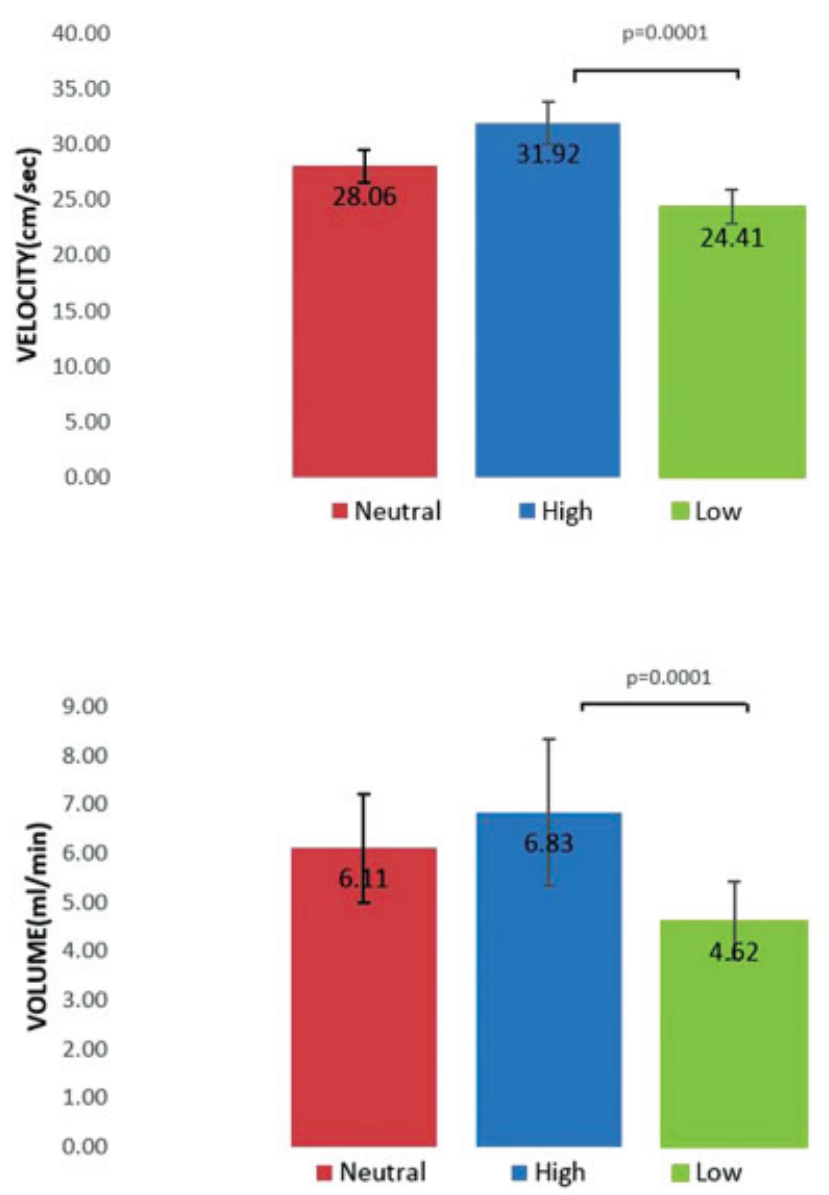

Fig. 3 The neutral, high value, and low value groups each showed mean flow velocity of $28.06 \pm 7.94,31.92 \pm 10.22$,

$24.41 \pm 8.12 \mathrm{~cm} / \mathrm{s}$, respectively, and mean flow volume rate of $6.11 \pm 4.95,6.83 \pm 6.69,4.62 \pm 3.55 \mathrm{~mL} / \mathrm{min}$, respectively. The mean velocity of the main perforator in the high value group was higher than that in the neutral group after rotation without statistical significance. However, the high value group had a significantly higher velocity than that in the low value group $(p=0.0001)(A)$. The flow volume also was significantly higher for the high value group when compared with that in the low value group $(p=0.0001)(B)$. literatures, the complication rate remains ranges from 7 to $23 \%$ and complete loss of approximately 3 to $5 \%{ }^{17-21}$

The major cause of skin flap failure is insufficient arterial blood flow along with poor venous outflow also responsible for inadequate perfusion and subsequent flap failure. Both mechanism leading to flap failure might be caused by poor flap design, thrombosis of the vascular pedicle, kinking of the pedicle, hematoma formation, hypovolemia and hypotension, hyperviscosity, low hematocrit, hypothermia, and infection. ${ }^{11}$

With a better understanding of flap anatomy and physiology, we can now use over 350 perforators in the body as a potential perforator flap. ${ }^{22,23}$ With the freestyle approach, the selected perforator can be dissected and used without tension or can be dissected to reach the source vessels achieving maximal pedicle length. ${ }^{16,24-26}$ Nevertheless, the reconstructive surgeon constantly strives to maximize the flow to the flap to obtain the best possible result. Despite all efforts, pedicle twisting in variable degrees may be unavoidable and can induce flow compromise and even occlusion of the pedicle. $8,11,12$

In our study, the flow velocity and flow volume rate were used to predict the favorable rotation direction of the flap. The flow velocity of perfusion showed significant difference in the rotation direction of the flaps indicating possible applications to maximize flap survival. A study by Geis et al shows that significantly higher perfusion values are related with complete flap survival over flaps with complications. ${ }^{27}$

The effect of torsion has been shown to reduce the blood flow by increasing the resistance in the vessel wall, giving rise to endothelial damage by causing turbulent flow, and leading to thrombus formation. ${ }^{11}$ When the pedicle has adequate longitudinal length, less torsion may occur but some level of torsion is still inevitable. A sufficient pedicle length will not make knot-like pressure in the inner structure of the pedicle itself, but if the length is short, a knot-like pressure will be created in the inner structure of the artery and vein, collapsing the lumens of the vessels and restricting blood flow, particularly in the vein. ${ }^{10}$ Therefore, in the case of inevitable unfavorable pedicle rotation, further skeletonizing and dissection should be performed to increase vascular flow. ${ }^{21}$ Nevertheless, routine skeletonizing may not be easy

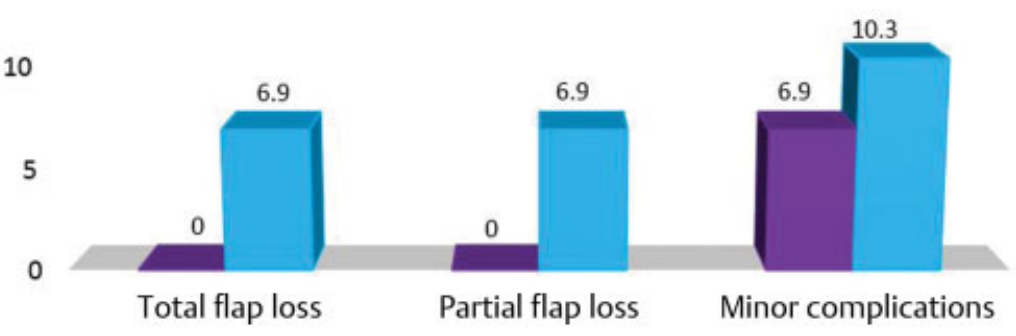

Duplex + clinical examination Clinical examination only

Fig. 4 When comparing the flap survival data between the prospective study (Duplex with clinical examination) and retrospective study (clinical examination only), there was no significant difference between the two groups in complications $(p=0.1443)$ although higher incidences of complications were noted in the retrospective study group. 
and also cumbersome. Furthermore, the anatomical pedicle structure may favor one direction rotation to the other raising the question if there is a preferred direction for rotation.

In our study, we measured flap flow velocity and flow volume rate in the setting of clockwise and counterclockwise rotation. We hypothesized that each flap might have a preferable direction over the other. First of all, the preferred direction of rotation (showing higher value of flow velocity and flow volume rate) was not different based on clockwise or counterclockwise direction. Rather, we postulate that the favorable direction relates to the specific branching anatomy of the perforator. After reassigning the data into higher and lowerflow groups, it revealed a significant difference between one direction of rotation compared with the other flow velocity and flow volume rate. The high value group showed a statistically higher mean flow velocity of $31.92 \pm 10.22 \mathrm{~cm} / \mathrm{s}$ compared with $24.41 \pm 8.12 \mathrm{~cm} / \mathrm{s}$ of the lower value group. The high value group also showed a statistically higher mean flow volume rate of $6.83 \pm 6.69 \mathrm{~mL} / \mathrm{min}$ compared with $4.62 \pm 3.55 \mathrm{~mL} / \mathrm{min}$ of the lower value group, respectively. To our knowledge, this is the first report claiming the directionality of flap rotation based on physiologic flow data. Rotating the pedicle raises the resistance, disturbs flow, and potentially damages the endothelial layer of the vessel wall. Although the reason underlying the difference in values is not investigated in this study, it is clear from the differences in flow dynamics that the pedicle has a preferred direction of rotation. In histologic analysis of rats, luminal collapse of the vein, perivascular inflammation, and endothelial damage were more severe with a larger angle of rotation. ${ }^{9}$ Human perivascular tissue is different from rat tissue, with thicker and irregular pattern connective tissues, thereby increasing the resistance upon rotation. The wavy irregular pattern may not favor a certain direction of rotation making one direction preferred over the other. To minimize torsion and kinking, one can skeletonize the pedicle to increase the flow, but this may increase the risk of vasospasm. Thus, searching for the preferred direction of rotation that naturally gives you more flow is of benefit. In our prospective cohort, there were only two minor complications of wound dehiscence after rotating on the preferred high value direction.

To further validate this approach, a comparison of flap outcomes was performed between the prospective ("Duplex + clinical exam") and retrospective ("clinical exam only") groups. In the retrospective group, the direction of flap rotation was determined by clinical findings such as capillary refill and marginal bleeding. The complication rate was higher in this group: there were two total flap losses, two partial flap losses, and three wound dehiscences (- Table 1). There is a consideration to be made as the retrospective group had more propeller flap reconstruction on the leg and this may play a role in increased complications as the perforators can be shorter. ${ }^{28-30}$ In the prospective group with objective assessment of perforator flow, there were no flap losses (partial or total) and only two wound dehiscences. However, when statistically comparing the outcome between the two groups, there was no significance. This is likely due to the inability to detect differences in a rare event with our current sample size. Clinical assessment of flap perfusion after propeller flap rotation should remain standard practice. We propose that the additional use of Duplex to detect the flow velocity and flow volume rate may increase surgeon confidence in determining the optimal direction of propeller flap rotation. Duplex assessment is simple to perform and add minimal operative time (-Video 1). - Fig. 5 shows a typical case using this approach. Given that previous literature has demonstrated relatively high complication rates with propeller flaps compared with microsurgical techniques, a simple intraoperative test to minimize the risk of flap loss is desirable. For the cases of total and partial flap loss, the mean flap size was relatively large $\left(130.9 \mathrm{~cm}^{2}\right)$ compared with the mean flap size in the cohort $\left(107.7 \mathrm{~cm}^{2}\right)$. We postulate that as the flap size becomes larger, the importance of arterial inflow will grow and may lead to a tipping point where direction of rotation is critical.

There are limitations of this study. First, we did not report the pedicle length for each case. The length of the pedicle is an important consideration, since a shorter pedicle will likely have increased kinking after rotation. ${ }^{9}$ However, we believe

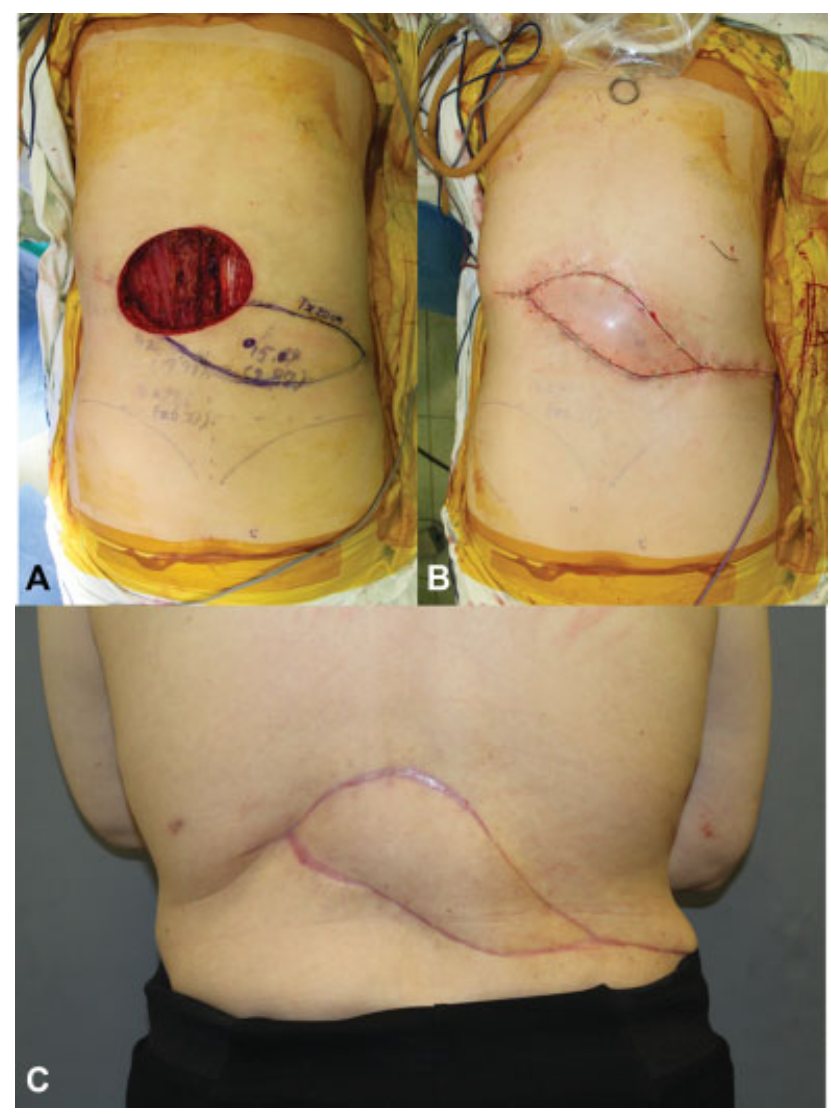

Fig. 5 A patient with sarcoma on the back is observed. After wide resection, a propeller flap is designed based on a pedicle using a handheld Doppler (A). After an exploratory dissection to identify the perforator, the rest of the flap is designed to assure primary closure. In this case, a horizontal design would be able to close the donor site primary. The immediate reconstruction shows $180^{\circ}$ rotation with closure of the donor site (B). The follow-up at 8 months shows good contour of the flap (C). 
this clinical judgement can be sufficiently made by visual inspection of the pedicle after flap rotation. We believe that tension and kinking play a more vital role than the actual length. Absolute tension free pedicle with adequate length and absence of kinking under the microscope were confirmed after rotation in all cases in our study despite the different pedicle lengths. Furthermore, the Duplex assessment of flow velocity allows one to select the rotation direction with the highest arterial inflow, and thereby the most favorable vessel conformation. Venous congestion is a common issue following propeller flap reconstruction and unfortunately intraoperative Duplex does not directly assess this component of flap perfusion. ${ }^{167}$ However, one can assume that flaps with higher arterial inflow are less likely to have issues with venous congestion. Second, is the uneven distribution of defect location between both groups. The retrospective group has a higher number of lower extremity cases. This may increase the complication of this group due to the fact that lower extremity propeller flaps may have higher complications. ${ }^{17,21}$ The basic principles of propeller flaps remain same despite the different locations and further evaluation with more cases will be able to verify this hypothesis. Third, although flow velocity and flow volume may represent some aspects of physiology of the flap, it is among the very complex variables involved. ${ }^{27} \mathrm{We}$ also understand that flap dynamics may change over time and further studies on how this affects the survival of the flap after rotation would be of future interest. ${ }^{31}$

\section{Conclusion}

The flow velocity and flow volume rate of the propeller flap differs significantly based on the direction of rotation of the pedicle. In addition to clinical assessment after flap rotation, Duplex assessment of perforator flow may increase surgeon confidence that the optimal direction of rotation has been selected. Using the preferred rotation direction may reduce the rate of flap loss, especially when large flaps are used.

Conflict of Interest

None declared.

\section{References}

1 Teo TC. The propeller flap concept. Clin Plast Surg 2010;37(04): 615-626, vi

2 Yu S, Zang M, Xu L, et al. Perforator propeller flap for oncologic reconstruction of soft tissue defects in trunk and extremities. Ann Plast Surg 2016;77(04):456-463

3 Koshima I, Hosoda M, Inagawa K, Moriguchi T, Orita Y. Free medial thigh perforator-based flaps: new definition of the pedicle vessels and versatile application. Ann Plast Surg 1996;37(05):507-515

4 Hyakusoku H, Yamamoto T, Fumiiri M. The propeller flap method. Br J Plast Surg 1991;44(01):53-54

5 Hyakusoku H, Ogawa R, Oki K, Ishii N. The perforator pedicled propeller (PPP) flap method: report of two cases. J Nippon Med Sch 2007;74(05):367-371

6 Hallock GG. The propeller flap version of the adductor muscle perforator flap for coverage of ischial or trochanteric pressure sores. Ann Plast Surg 2006;56(05):540-542
7 Demir A, Acar M, Yldz L, Karacalar A. The effect of twisting on perforator flap viability: an experimental study in rats. Ann Plast Surg 2006;56(02):186-189

8 Keleş MK, Demİr A, Küçüker I, Alici O. The effect of twisting on single and double based perforator flap viability: an experimental study in rats. Microsurgery 2014;34(06):464-469

9 Chang CH, Lim SY, Pyon JK, Bang SI, Oh KS, Mun GH. The influence of pedicle length on the viability of twisted perforator flaps in rats. J Reconstr Microsurg 2009;25(09):533-538

10 Gokrem S, Sarifakioğlu N, Toksoy K, Terzioğlu A, Aslan G. Effects of 360-degree pedicle torsion on island skin flaps: experimental study in rats. J Reconstr Microsurg 2005;21(05): 313-316

11 Bektas G, Ozkan O, Cinpolat A, Bassorgun IC, Ciftcioglu MA, Ozkan O. Comparing the effects of pedicle torsion on axial or perforator flaps; improving the perforator flap resistance to pedicle torsion with delay phenomenon. J Reconstr Microsurg 2014;30(08): 531-538

12 Schonauer F, La Rusca I, Di Monta G, Molea G. Choosing the correct sense of rotation in 180 degrees propeller flaps. J Plast Reconstr Aesthet Surg 2008;61(12):1492

13 Schonauer F, Moio M, La Padula S, Molea G. Use of preoperative Doppler for distally based sural flap planning. Plast Reconstr Surg 2009;123(05):1639-1640, author reply 1640

14 Eom JS, Hong JP. Lower back defect coverage using a free-style gluteal perforator flap. Ann Plast Surg 2011;67(05):516-519

15 Hong JPJ, Choi D, Lee Y, Kim Y, Jang M, Peter Suh H. Using the gluteal artery perforator flap to reconstruct sacral sore. Plast Reconstr Surg Glob Open 2017;5(06):e1368

16 Park SW, Oh TS, Eom JS, Sun YC, Suh HS, Hong JP. Freestyle multiple propeller flap reconstruction (jigsaw puzzle approach) for complicated back defects. J Reconstr Microsurg 2015;31(04):261-267

17 Nelson JA, Fischer JP, Brazio PS, Kovach SJ, Rosson GD, Rad AN. A review of propeller flaps for distal lower extremity soft tissue reconstruction: is flap loss too high? Microsurgery 2013;33(07): 578-586

18 Sisti A, D'Aniello C, Fortezza L, et al. Propeller flaps: a literature review. In Vivo 2016;30(04):351-373

19 Mohan AT, Sur YJ, Zhu L, et al. The concepts of propeller, perforator, keystone, and other local flaps and their role in the evolution of reconstruction. Plast Reconstr Surg 2016;138(04): $710 \mathrm{e}-729 \mathrm{e}$

20 Vitse J, Bekara F, Bertheuil N, Sinna R, Chaput B, Herlin C. Perforator-based propeller flaps reliability in upper extremity soft tissue reconstruction: a systematic review. J Hand Surg Eur Vol 2017;42(02):157-164

21 D'Arpa S, Cordova A, Pignatti M, Moschella F. Freestyle pedicled perforator flaps: safety, prevention of complications, and management based on 85 consecutive cases. Plast Reconstr Surg 2011; 128(04):892-906

22 Taylor GI, Palmer JH. The vascular territories (angiosomes) of the body: experimental study and clinical applications. Br J Plast Surg 1987;40(02):113-141

23 Saint-Cyr M, Wong C, Schaverien M, Mojallal A, Rohrich RJ. The perforasome theory: vascular anatomy and clinical implications. Plast Reconstr Surg 2009;124(05):1529-1544

24 Lecours C, Saint-Cyr M, Wong C, et al. Freestyle pedicle perforator flaps: clinical results and vascular anatomy. Plast Reconstr Surg 2010;126(05):1589-1603

25 Wei FC, Mardini S. Free-style free flaps. Plast Reconstr Surg 2004; 114(04):910-916

26 Wallace CG, Kao HK, Jeng SF, Wei FC. Free-style flaps: a further step forward for perforator flap surgery. Plast Reconstr Surg 2009; 124(6, Suppl):e419-e426

27 Geis S, Prantl L, Dolderer J, Lamby P, Mueller S, Jung EM. Postoperative monitoring of local and free flaps with contrastenhanced ultrasound (CEUS)-analysis of 112 patients. Ultraschall Med 2013;34(06):550-558 
28 Cajozzo M, Toia F, Innocenti A, et al. Retrospective analysis in lower limb reconstruction: propeller perforator flaps versus free flaps. J Reconstr Microsurg 2017;33(S 01):S34-S39

29 Chaput B, Bertheuil N, Carloni R, Bekara F, Laloze J, Herlin C. Propeller perforator flaps of extremities seem less reliable. J Reconstr Microsurg 2017;33(08):603-604
30 Paik JM, Pyon JK. Risk factor analysis of freestyle propeller flaps. J Reconstr Microsurg 2017;33(01):26-31

31 Hanasono MM, Ogunleye O, Yang JS, Hartley CJ, Miller MJ. Changes in blood velocity following microvascular free tissue transfer. J Reconstr Microsurg 2009;25(07):417-424 